\title{
Changing the Attitudes and Beliefs of Pre-service Primary Teachers Towards Mathematics
}

\author{
Dorian Stoilescu \\ Western Sydney University \\ d.stoilescu@westernsydney.edu.au
}

\begin{abstract}
The importance of preparing primary educators capable of successfully teaching mathematics has been extensively emphasized in educational research. However, it is widely acknowledged that pre-service teachers in primary education start their career with poor attitudes and a great degree of anxiety towards mathematics. As such, primary education has been under severe criticism for not being able to provide their pre-service teachers with an adequate set of skills and attitudes towards mathematics. This paper discusses several cases and searches for possible explanations that are perpetuating this state. As well, this theoretical paper gives some recommendations for decreasing mathematics anxiety and improving mathematical knowledge for pre-service teachers in primary education.
\end{abstract}

Keywords: mathematics anxiety, mathematics primary education, pre-service teacher education

\section{Introduction}

In the last decades, the number of jobs requiring mathematics knowledge and abilities to be applied in various areas of expertise such as engineering, technology, finance, and science has increased in Australia and internationally (Carnevale, Strohl, \& Melton, 2011; Rothwell, 2013; Stasz \& Brewer, 1999). As a result for Australian universities, the request for preparing educators capable of achieving adequate skills in mathematics that make them capable of teaching students in various domains of numeracy has proved extremely challenging (Harris \& Jensz, 2006). In this context, researchers have been concerned that the level of knowledge achieved by teachers is not enough to fulfil the requirements for these jobs (Rothwell, 2013). As such, there is a great concern that the mathematical achievements might not meet the needed level (Ball, 1990; Harris \& Jensz, 2006), as the research noticed that the problems of preparing students with adequate mathematical skills, dispositions and knowledge start early in primary schools.

The issues of preparing primary teachers have been discussed from multiple perspectives (Ball, 1990; Harris \& Jensz, 2006). Some research reports claim that teacher programs do not adequately provide sufficient mathematics knowledge for pre-service teachers. For instance, in Australia, the report titled The Discipline Review of Teacher Education in Mathematics and Science (Department of Employment, Education and Training [DEET], 1989), claimed that a great number of students entering pre-service primary programs have only a superficial knowledge of mathematical content and skills. Exactly, the report emphasizes the importance of pre-service teachers becoming mathematically competent and having higher order mathematical knowledge to give them confidence in their teaching and to provide them with the tools with which they will be able to help their future students. 
One of the main aspects of difficulties encountered in improving mathematics teacher education is that many of the Australian primary teachers do not have an adequate mathematical background (Gibson \& Wechmann, 2012). For instance, there is a low percentage of student teachers registered in primary teacher education programs who had previously studied advanced courses in mathematics. This situation is similar with other countries such as the US and the UK (Ball, 1990; Zakaria \& Nordin, 2008).

Ball (1990) found that elementary pre-service teachers look at the mathematics as a collection of random procedures and facts. For them, there is little understanding of mathematics as a connected body of knowledge so necessary to start the teaching profession in primary schools. As a consequence, these teachers are not only unable to demonstrate a high level of understanding mathematics but a negative attitude towards learning mathematics as well. They showed what many researchers recognized as mathematics anxiety in primary and secondary schools (Bursal \& Paznokas, 2006; Trujillo \& Hadfield, 1999; Vinson, 2001).

\section{Mathematics Anxiety in Pre-service Teacher Education}

Mathematics anxiety is a very complex phenomenon that has different causes, aspects, and trajectories. For instance, Trujillo and Hadfield (1999) classified mathematical anxiety into three main factors: (1) environmental, (2) intellectual, and (3) personality. Under environmental factors could be mentioned negative experiences in the classroom, parental pressure, teachers lack of ability to communicate to their students and insensitive to their learning needs, mathematical presentations that were mechanically and rigidly presented as a boring sets of rules to be mechanically applied. Students are not encouraged to participate, collaborate, and share their ideas with their classmates as well. Under intellectual factors could be mentioned cases where students are being taught without adequate learning styles and not having positive attitudes being fostered by the teacher (Dweck, 2006). Instead, there is a lack of persistence, self-doubt, lack of confidence in mathematical ability and the usefulness of mathematics, lack of confidence in mathematics, and students and teachers' knowledge and skills. Personality factors include students' reluctance to ask questions due to shyness, low self-esteem, and viewing mathematics as foreign to their core interests and daily practices.

Studying mathematics anxiety, Jackson and Leffingwell (1999) found cases of primary classrooms where primary teachers taught mathematics by displaying hostile behaviors towards their students or to the mathematical content. In addition, teachers themselves showed difficulty in mastering the mathematical content. Teachers displayed insensitive and careless attitudes towards various students, including gender bias, and had difficulties in communicating their requests to students and their parents. Therefore, teachers have an important role in provoking mathematics anxiety among their students through inadequate and poor attitudes, knowledge, behaviors, and class management. Boaler $(2014,2015,2016)$ found a similar lack of positive 
attitudes and leadership towards mathematics and emphasized the strong interrelationships between growth mindset and brain plasticity. Her research involving growth mindset and successful mathematics learning strongly supports Dweck's ideas.

Pre-service teachers' beliefs and anxiety are influenced by prior personal mathematical experiences (Raymond, 1997). Personal negative beliefs are often overwhelming pre-service teachers (White, Perry, Way, \& Southwell, 2006). These are complex states. For some students, the anxiety of studying mathematics appeared to arise during secondary school experiences (Nicol, Gooya, \& Martin, 2002) and even in university. In contrast, Uusimaki and Nason (2004) reported that students' negative attitudes towards mathematics start from the primary level. For example, many pre-service teachers mentioned the difficulty of handling the basic calculations while in primary school. These students mentioned that their inabilities remains now even when they will soon start teaching in a primary school. One of subjects acknowledged his lack of mathematical skills: "Long division! Couldn't do that. Dividing. Can't do that. And with addition and subtraction, I still use my fingers" (Uusimaki \& Nason, 2004, p. 6). There are many similar studies illustrating many personal stories of students' mathematical anxieties and lack of adequate skills in teaching mathematics. Boaler $(2014,2015)$ had a considerable amount of examples of exploring ways of successfully teaching mathematics by emphasizing passion and positive attitudes and surpassing mathematical anxiety.

\section{Helpfulness of Mathematics Methods Courses in Reducing Mathematics Anxiety}

Some researcher criticized actual teaching programs for the reduced number of opportunities offered to pre-service students to improve their mathematical knowledge. Ball (1990), believed that pedagogical aspects of primary programs are overemphasized to the detriment of mastering the mathematical content. She claims that ignoring the requirements to master mathematical content ultimately leads pre-service primary teachers to mathematics anxiety and fails them by not adequately preparing them for their further profession.

Other research emphasizes the importance of methods courses in mathematics and their important role for reduce mathematical anxiety. Harper and Daane (1998) recommended that "prospective teachers need to be aware of factors that cause mathematical anxiety and not contribute to them" (p. 35). Therefore, they recommended that pre-service teachers develop awareness of their own negative dispositions towards mathematics and correct them in order to prevent transmitting them to their future students.

Ernest (2002) proposed the following paths of mathematical empowerment: (1) cognitive, (2) meta-cognitive, and (3) semiotic. From the cognitive perspective, the mathematical empowerment concerns the acquirement of concepts, facts, algorithms, and techniques of solving mathematical problems. The second path is metacognition which includes planning strategies, monitoring various techniques of solving problems, judging the correctness 
of various solutions, and improving the strategies of solving problems. The third perspective, called the semiotic path, involves developing mathematics in social contexts. This includes the potential to transform mathematical ideas into various processes, tasks, and texts and obtain different types of outcomes such as representations, explanations, solutions, and theories.

\section{Pre-service Teacher Education Programs}

Important changes were proposed in order to improve mathematics teacher preparation (Hiebert \& Carpenter, 1992), as teachers are considered the main agents of improving the results in the educational system. In order to be successful in achieving mathematical knowledge, teaching for understanding considers pedagogical shifts that the mathematics educators need to adopt (Hiebert \& Carpenter, 1992; Graeber, 1999; Skemp 1976, 1986, 1989). Teaching for understanding remains an important paradigm in mathematics education, where teaching means, most of all, making sense of mathematical rules and concepts in order to gradually apply them in various contexts. These concerns were used to examine the pre-service teacher education programs to explore ways in which teachers are failing to develop the necessary skills, concepts, and procedures required by them in order to help them recover from mathematical deficiencies and be effective teachers.

For this reason, the teachers should be the first to understand the mathematical content and be able to adapt it for various categories of contexts. In the last 30 years there has been a substantial volume of research on preparing pre-service teachers to improve their pedagogical knowledge in teaching mathematics for primary schools. Other research studies and teaching programs have been excessively focused on the way the content mixes with pedagogical, psychological, cultural, and social aspects of learning and teaching mathematics (Ball, 1990). While these aspects are very important and required for any primary teachers, they are not a substitute for the pursuit of providing adequate mathematical knowledge.

Keeping in mind Ernest' (2002) paths of improvements, the author found similar strategies of mathematical empowerment in pre-service teacher education programs. For instance, there are research studies focusing on the cognitive path of empowering pre-service teachers. More exactly, these research studies consider the effectiveness of a mathematics method course in reducing the mathematics anxiety levels among pre-service teachers (Bursal \& Paznokas, 2006; Ernest, 2002). By reviewing the main topics from primary and junior secondary mathematics curricula, these method courses target the improvement of pre-service teachers' understanding of mathematical skills and techniques.

According to the National Council for Teachers in Mathematics [NCTM] (2000), instructors of pre-service mathematics teachers should provide opportunities to enhance the instructional practices and positive attitudes needed by pre-service teachers. This includes capabilities to develop problem solving skills and advanced mathematical discourse by 
demonstrating positive beliefs and attitudes about learning and teaching mathematics. Comparing with Ernest's (2002) model, the author sees this approach oriented toward the third direction, the semiotic/social path. Further, NCTM (2000) gave some recommendations for improving mathematics teaching as follows:

- making mathematical content relevant for pre-service teachers;

- allow for different social approaches to learning mathematics;

- emphasize the importance of original, quality thinking rather than rote manipulation of formulas;

- emphasize that everyone makes mistakes in mathematics;

- characterize mathematics as a human endeavor;

- let student share some input into their own evaluations;

- design positive experiences in mathematics classes; and

- accommodate for different learning styles.

Researchers proposed familiarizing pre-service teacher with manipulative and ICT in order to decrease mathematical anxiety and increase mathematical empowerment. Studies by Bursal and Paznokas (2006) and Vinson (2001) found that pre-service teachers' mathematics anxiety levels are significantly reduced when an emphasis is placed on using manipulative and trying to emphasize students' understanding. In line with this, Grandgenett (2008) explored convincing examples of mathematics teachers that are using technology in empowering way for their students.

Some researchers argued that we should not reduce improving the quality of teaching mathematics to the improvement of teachers' mathematical knowledge. For instance, Mapolelo (1999) showed that knowing the mathematical content is not enough to be proficient in teaching mathematics. She shows the example of pre-service primary teachers who were very good in mathematics, yet their teaching was still peculiar, as their teaching approach was rather procedural and they were not focusing on teaching for understanding. For that reasons, it remains an important step for teachers when they mechanically know how to apply algorithms and when they are required to explain and justify these algorithms. In addition, it is important to understand the brain compression (Thurston, 1990) as a way our brain spends a large amount of time learning automatic ways of applying mathematical ideas but once we gather familiarity, understanding, and valuable insights, these capabilities of applying mathematical procedures take creative, valuable, and unexpected turns in solving new mathematical problems.

Borko, Eisenhart, Brown, Underhill, Jones, and Agard (1992) described the tension experienced by a novice teacher when pushed to explain to students why a particular procedure worked. The authors conclude that the teacher's lack of conceptual knowledge and lack of desire to engage in difficult mathematics destroyed the opportunity for their students to experience a rich and deep understanding of the topic. 
Graeber (1999) made some recommendations for pre-service teachers in order to improve their mathematical preparation in pre-service teaching programs through a semiotic approach. For him, teachers should let pre-service teachers explore students' ways of understanding mathematics. Furthermore, they should be aware of common misconceptions and limited mathematical conceptions and explore for themselves these categories. However, teaching programs need to help pre-service teachers build a genuine appreciation of what really mathematics content is and encourage them to explore multiple ways of solving problems. They also need to anticipate ways in which students apply mechanical techniques without choosing the right context or without having the adequate understanding of these strategies.

An important international program used for both pre-service and in-service mathematics education teachers is Lesson Study. This program consists of embedding a cultural approach to developing educational professional approaches. The program consists of examinations of learning artefacts and in peer examinations of mathematical and pedagogical experiences in teaching. Learning and development involving a learning culture approach (now and in the future) with schools and teachers making their own choices can be placed in the last phase and belongs to the tradition of teacher professional learning that concentrates upon an examination of practice through the direct observation by colleagues of each other's practice, and through the examination of classroom artefacts or through case studies of teachers by teachers (Stigler, Gallimore, \& Hiebert, 2000). While the Lesson Study program originated in Japan (Stigler \& Hiebert, 1999), it has manifested itself in various forms according to cultural contextual differences in countries such as the US (Fernandez, 2000), Australia (White et al., 2006), and Malaysia (Chiew \& Lim, 2003; White et al., 2013).

\section{Strengths and Limitations of the Literature Reviewed}

The literature reviewed in the earlier sections tends to focus on pre-service teacher education programs. Some of the research studies quoted in this study have been done in the University of Western Sydney (White et al., 2006; Southwell, White, Way, \& Perry, 2006). The Australian primary school curriculum, including the mathematics curriculum, has undergone major changes at the beginning of the $21^{\text {st }}$ century. For example, the New South Wales mathematics school curriculum has undergone two major shifts in the recent decades. The 'new' curriculum that came into practice in 2001 in New South Wales became outdated with the introduction of new Australian National Curriculum in mathematics in 2014. Therefore, teacher education programs are trying to introduce innovative strategies to decrease the mathematics anxiety of primary pre-service students and empower them mathematically. As such, with the advent of digital revolution in primary school classrooms in the $21^{\text {st }}$ century, the pedagogical approaches drastically changed in mathematics education units. Unfortunately, although well intended, some measures add to students anxiety as the number of classes dedicated for improving students' mathematical content is often reduced and underfinanced. 
Likewise, this brief review concentrates on attitudes and beliefs of pre-service teachers, many of them are from Australia. Other countries such as the US and the UK are represented as their pedagogical and research practices are very similar. For example, studies from countries such as the US and the UK (e.g. Ball, 1990; Earle, 2002) offered strong support to findings of Australian studies. However, I found a lack of discussions in the current pre-service programs about the consequences of mathematics anxiety. I found that very few programs tried to implement effective strategies for mathematical empowerment.

\section{Implications of the Literature Reviewed for Personal Teaching and Learning Practice}

Put succinctly, the relevant and up-to-date review of pre-service students in mathematics in primary education equips the author with awareness, knowledge, and skills to address any related issues in the current pre-service primary teacher education programs. Therefore, my personal teaching strategies will attempt to convince my pre-service students about the importance of positive attitudes and personal example in teaching mathematics. I will try to discuss the issues raised with my students and ask them to reflect upon their personal history of learning mathematics and see where they failed to learn adequately.

As well, it is important that university educators discuss with their students ways of improving the metacognitive skills in mathematics. Currently, there is a lack of emphasis in pre-service teaching programs upon improving metacognitive skills. More exactly, students should not learn only a set of rules, but should learn how to create their problem solving strategies, check their solutions, and evaluate the thinking behind their solutions. Therefore, a strong emphasis should be in place in order to nurture ways of creating strategies and developing critical thinking in solving mathematical problems.

For the semiotic path (Earnest, 2002), the social approach of teaching mathematics is largely used in pre-service programs. Trying to implement a cultural change in the way preservice primary teachers view mathematics is extremely challenging but rewarding as well. By just reading some brief summaries and hearing some advice from lecturers, pre-service teachers will never develop a passion for mathematics. They need to be extended in different ways of trying problems and analyzing different types of errors, attitudes, anxieties, and ideas. Preservice teachers need to share their experiences and personalize their approaches in solving mathematical problems.

Currently, many teaching programs, including the Western Sydney University preservice master teaching programs, attempt integrating various degrees of constructivist or socio-cultural approaches into their theoretical framework and employ hands-on methods of learning mathematics. As well, students have the opportunity to learn rigorous ways of proof and investigating ways of constructing problem solving strategies. They are encouraged to try. As well, students have the opportunity to approach real life problems in mathematics. Pre- 
service teachers rate the current program highly important and instrumental in enhancing their confidence and skills in teaching mathematics.

As mentioned, these ideas collected during current review further inform lecturers' teaching practices. For instance, a better understanding of anxieties, cognitive paths, and needs of pre-service students are important ways of improving knowledge and understanding concepts on how to be more supportive teacher. Also improving lecturers' and pre-service teachers understanding of the necessity of ongoing professional learning of teaching mathematics would help in improving the program in future semesters.

This brief review has discussed the major initiatives at Australian universities but there were not many recent studies on the change of personal perspectives of primary educators for their initial year of teaching in a primary school setting and the support that universities can offer during this phase. Future research directions could include a longitudinal study based on the designing some interventions for mathematics tutorials for the pre-service primary education program with the focus on enhancing mathematical skills and attitudes, and helping students succeed in switching from mathematical anxiety to mathematical empowerment. Other studies may involve the follow up and collection of information from pre-service teachers who enter their profession soon after their pre-service training. Further studies could collect information on causes that prevent pre-service teachers from engaging in solving mathematical problems, such as person-specific (e.g. anxiety, attitudes, motivation, knowledge, and skills) and the situation-specific issues (e.g. lack of time, support, and resources), personal views of the role of mathematics, and the way they perceived the mathematics in their family, school, and community. Although there is an increasing body of international literature on anxiety aspects faced by primary mathematics teachers in real school contexts, a further study could focus on the experiences of pre-service teachers in local school settings. It is important that university educators and researchers network with teachers so that connecting teaching professional practices and research can inform current education programs by incorporating practical elements from real settings and thus further modifying present programs with empowering experiences. As such, an improved knowledge of such issues would help preservice teachers programs to develop various forms of planned support for beginning teachers in their initial years of teaching mathematics in primary schools.

\section{References}

Ball, D. (1990). The mathematical understandings that prospective teachers bring to teacher education. The Elementary School Journal, 90, 449-465.

Boaler, J. (2014). Unlocking children's mathematics potential: Five research results to transform mathematics learning. Reflections, 39(2), 16-20. 
Boaler, J. (2015). What's math got to do with it? How teachers and students can transform mathematics learning and inspire success (revised ed.). New York: Penguin Books.

Boaler, J. (2016). Mathematical mindsets. San Francisco, CA: Jossey-Bass.

Borko, H., Eisenhart, M., Brown, C. A., UnderhilI, R., Jones, D., \& Agard, P. C. (1992). Learning to teach hard mathematics: Do novice teachers and their instructors give up too easily? Journal for Research in Mathematics Education, 23, 194-222

Bursal, M., \& Paznokas, L. (2006). Mathematics anxiety and pre-service elementary teachers confidence to teach mathematics and science. School Science and Mathematics, 106(4), 173-179.

Carnevale, A., Strohl, J., \& Melton, M. (2011). What's it worth: The economic value of college majors. Washington, DC: Georgetown University Center on Education and the Workforce.

Department of Employment, Education and Training. (1989). Discipline review of teacher education in mathematics and science (Vol. 1). Canberra: Australian Government Printing Service.

Dweck, C.S. (2006). Mindset: The new psychology of success. New York: Ballantine Books.

Ernest, P. (1989). The knowledge, beliefs and attitudes of the mathematics teacher: A model. Journal of Education for Teaching, 15(1), 13-33.

Ernest, P. (2002). Empowerment in mathematics education. Philosophy of Mathematics Journal, 15(1), 1-16.

Gibson, I. \& Wechmann, K. (2012). Who are Australia's future teachers? Main report on the 2011 survey. Retrieved from http://thewarrencentre.org.au/wpcontent/uploads/2013/02/wc1858-0-IGibson-TEQ-FinalReport-August2012.pdf

Graeber, A. (1999). Forms of knowing mathematics: What pre-service teachers should learn. Educational Studies in Mathematics, 38(1-3), 189-208.

Graeber, A. O., Newton, K. J., \& Chambliss, M. J. (2012). Crossing the borders again: Challenges in comparing quality instruction in mathematics and reading. Teachers College Record, 114(4), 30.

Grandgenett, N.F. (2008) Perhaps a matter of imagination: TPCK in mathematics education. In American Association of Colleges for Teacher Education [AACTE] Committee on Innovation and Technology (Eds.) Handbook of Technological Pedagogical Content Knowledge (pp. 145-166). New York: Routledge.

Harris, K. L., \& Jensz, F. (2006). The preparation of mathematics teachers in Australia: Meeting the demand for suitably qualified mathematics teachers in secondary schools: Report prepared for Australian Council of Deans of Science. Centre for the Study of Higher Education, University of Melbourne.

Harpera, W. N., \& Daaneb, C. J. (1998). Causes and reduction of math anxiety in pre-service elementary teachers. Action in Teacher Education, 19(4), 29-38. 
Hiebert, J., \& Carpenter, T. P. (1992). Learning and teaching with understanding. In D. Grows (Eds.), Handbook of research on mathematics teaching and learning (pp. 6597). New York: Macmillan.

Jackson, C. D., \& Leffingwell, R. J. (1999). The role of instructors in creating mathematics anxiety in students from kindergarten through college. Mathematics Teacher, 92, 583586.

Mapolelo, D.C. (1999). Do pre-service primary teachers who excel in mathematics become good mathematics teachers? Teaching and Teacher Education, 15(6), 715-725.

National Council of Teachers of Mathematics (NCTM) (2000). Curriculum and evaluation standards for school mathematics. Reston, VA: Author.

Nicol, C.Z., Gooya, Z. \& Martin, J. (2002). Learning mathematics for teaching: Developing content knowledge and pedagogy in a mathematics course for intending teachers. In Proceedings of the $26^{\text {th }}$ Conference of the International Group for the Psychology of Mathematics Education. Norwich: UK.

Raymond, A. M. (1997). Inconsistency between a beginning elementary school teacher's mathematics beliefs and teaching practice. Journal for research in mathematics education, 550-576.

Rothwell, J. (2013). The hidden STEM economy. Washington, DC: Brookings.

Skemp, R. (1976). Relational understanding and instrumental understanding. Mathematics Teaching, 77, 20-26.

Skemp, R. (1986). The psychology of learning mathematics $\left(2^{\text {nd }}\right.$ ed). London: Penguin Books.

Skemp, R. (1989). Mathematics in the primary school. London: Routledge.

Southwell, B., White, A. L., Way, J., \& Perry, B. (2006) Attitudes versus achievement in preservice mathematics teacher education In Refereed Proceedings, Annual Conference of the Australian Association for Research in Education. Sydney: AARE.

Stasz, C., \& Brewer, D. J. (1999). Academic skills at work: Two perspectives. National Center for Research in Vocational Education, Graduate School of Education, University of California.

Thurston, W. (1990). Mathematical education. Notices of the American Mathematical Society, 37(7), 844-850.

Trujillo, K. M., \& Hadfield, O. D. (1999). Tracing the roots of mathematics anxiety through in-depth interviews with pre-service elementary teachers. College Student Journal, 33, 219-232.

Uusimaki, L., \& Nason, R. (2004, July). Causes underlying pre-service teachers' negative beliefs and anxieties about mathematics. In Proceedings of the $28^{\text {th }}$ Conference of the International Group for the Psychology of Mathematics Education (Vol. 4, pp. 369376). 
Vinson, B. (2001).A comparison of pre-service teachers' mathematics anxiety before and after a methods class emphasizing manipulatives. Early Childhood Education Journal, 29(2), 89-94.

White, A. L., Perry, B., Way, J., \& Southwell, B. (2006). Mathematical attitudes, beliefs and achievement in primary pre-service mathematics teacher education. Mathematics Teacher Education \& Development, 7, 33-52.

White, A. L., Jaworski, B., Agudelo-Valderrama, C., \& Gooya, Z. (2013). Teachers learning from teachers. In M.A. Clements, A.J. Bishop, C. Keitel, J. Kilpatrick, \& F.K.S. Leung (Eds.), Third International Handbook of Mathematics Education (pp. 393-430). New York: Springer.

Zakaria, E., \& Nordin, N. M. (2008). The effects of mathematics anxiety on matriculation students as related to motivation and achievement. Eurasia Journal of Mathematics, Science \&Technology Education, 4(1), 27-30. 

Southeast Asian Mathematics Education Journal 2017, Vol. 7 No. 1 